\title{
PRÁTICAS DA PRESERVAÇÃO NA FRANÇA, MÉXICO E BRASIL: CONVERGENCIAS DE UM DEBATE.
}

SIMONE SCIFONI, UNIVERSIDADE DE SÃO PAULO, SÃO PAULO, SÃO PAULO, BRASIL

Geógrafa, doutora em Geografia, docente do Departamento de Geografia da Faculdade de Filosofia, Letras e Ciências Humanas da Universidade de São Paulo. E-mail: simone.geo@usp.br.

DOI

http://dx.doi.org/10.11606/issn.1980-4466.v0iesp21p49-66 


\section{PRÁTICAS DA PRESERVAÇÃO NA FRANÇA, MÉXICO E BRASIL: CONVERGÊNCIAS DE UM DEBATE. \\ SIMONE SCIFONI}

\section{RESUMO}

Partindo de questões presentes no debate de três apresentações sobre as práticas de preservação do patrimônio cultural em países como França, México e Brasil, este artigo busca sublinhar algumas convergências e aproximações entre tais experiências. Assim sendo, serão discutidas questões como: a necessidade de repensar a afirmação de que vivemos a patrimonialização excessiva; a relevância em instituir mecanismos de participação social nas ações preservacionistas; e, por fim, a urgência de incorporar um olhar mais integral na seleção dos bens a serem tombados. O objetivo é problematizar os conteúdos de cada um destes temas.

\section{PALAVRAS-CHAVE}

Preservação do patrimônio. Políticas públicas. Bens culturais. 


\title{
PRESERVATION PRACTICES IN FRANCE, MEXICO AND BRAZIL: CONVERGENCES IN A DEBATE. SIMONE SCIFONI
}

\begin{abstract}
Based on the issues present in the debate of three presentations on cultural heritage preservation practices in countries such as France, Mexico and Brazil, this article aims to highlight some convergences and similarities between those experiences. Therefore, the article will examine issues such as: the need to reconsider the claim that we are currently living a period of excessive preservation; the relevance of establishing social participation mechanisms in preservation actions; and, finally, the urgency to incorporate a more comprehensive look into the set of assets chosen to be listed as heritage. As such, the aim is to call into question the contents of each of these topics.
\end{abstract}

\section{KEYWORDS}

Heritage. Preservation. Public policy. Cultural assets. 


\section{INTRODUÇÃO}

Há possibilidade de encontrar circunstâncias em comum entre três diferentes experiências de preservação, a primeira em um país europeu e, outras duas, em nações latino-americanas, como são os casos da França, México e Brasil? Proximidades entre uma prática que já se afirmou ser inflacionada ou esgotada, conforme Choay (2001) e Jeudy (2005), com outras duas que expressam sua incompletude e desigualdade de representação, segundo Canclini (1994) e Rubino (1996)?

As três apresentações da primeira mesa-redonda ${ }^{1}$ do Seminário Reconhecimento dos Bens Culturais apontaram para convergências e aproximações, apesar de seus contextos específicos e de realidades socioeconômicas e políticas diferenciadas. Assim sendo, o objetivo do presente artigo é sublinhar e debater as problemáticas em comum nessas três experiências trazidas no seminário, no sentido de tirar lições de um quadro comparativo que os palestrantes da mesa, em conjunto, puderam traçar. 


\section{RELATIVIZAR A INFLAÇÃO PATRIMONIAL}

Ao contrário do que o debate contemporâneo tem insistido, ou seja, em uma patrimonialização excessiva, as apresentações desta primeira mesa-redonda do seminário apontaram para uma realidade mais complexa, ambígua e contraditória. Exclusões, invisibilidades, ausências.

Richard Klein relatou as dificuldades, na França, de reconhecimento e proteção da herança do século XX, das invisibilidades de arquiteturas modestas que ficaram excluídas do critério de valor artístico, como conjuntos de moradia coletiva, equipamentos públicos de lazer e turismo ou da modernidade do cotidiano. Gabriella Lee tratou de um patrimônio urbano periférico, intrinsecamente ligado à vida cotidiana de determinados grupos sociais e atualmente sob risco, como o caso de antigos pueblos no Vale do México, conurbados à metrópole. Marly Rodrigues lembrou o peso preponderante que a arquitetura assume nos critérios de valoração no Brasil, uma ortodoxia que produz ausências no conjunto patrimonial.

Em que pese à crítica tão necessária aos usos e abusos do patrimônio cultural reificado colocado à exibição para o consumo visual, tal como se vê em Choay (2001) e Jeudy (2005), os autores franceses têm insistido em um quadro contemporâneo de patrimônio em excesso. Segundo Jeudy (2005, p. 29):

Passado o tempo das energias reunidas para defender todo o poderio das identidades culturais, para provocar um sobressalto nas memórias coletivas, somos forçados a reconhecer que a petrificação patrimonial já concluiu sua obra. Passou-se para o estágio da "manutenção patrimonial”.

Já para Choay (2001), vive-se uma inflação patrimonial após os anos 1960, provocada pela expansão dos critérios tipológicos e cronológicos de seleção que foram responsáveis pela inclusão de uma variedade de novos objetos no conjunto patrimonial, o que a autora chama, ironicamente, de complexo do Noé. Por trás desta expressão, está a crítica ao reconhecimento de algumas construções, que a autora chama de arquitetura medíocre ou em péssimo estado de conservação, que, para ela, não deveriam ser tombadas. É importante lembrar, contudo, que foi justamente a ampliação de critérios de seleção que tornou a herança coletiva um pouco 
mais democrática, deixando o patrimônio de simbolizar unicamente os bens da elite, para se aproximar de um universo cotidiano e popular. $\mathrm{O}$ que a autora chama, ironicamente, de complexo do Noé é fruto de uma diversificação e democratização do conjunto patrimonial.

No Brasil, também encontra eco um discurso de excesso de memorialização e de preservação, justamente a partir de um momento em que o patrimônio dá pequenos sinais de aproximação com o universo popular. "A cena brasileira contemporânea demonstra o quanto o país vem acompanhando, em ritmo de campeão, o grande boom memorial internacional." (SANTOS; MARQUES, 2014, s/p). Contudo, quando se olha o patrimônio como parte da totalidade urbana nas cidades brasileiras, o quadro parece bem mais contraditório. Afirmar um boom memorial, no Brasil, acena para uma visão um tanto quanto otimista das condições atuais.

Vivemos uma dinâmica urbana tensionada pelas forças do mercado imobiliário que impõem a lógica da "cidade como negócio" e têm eliminado traços fundamentais da história cotidiana, tais como antigos cinemas ou teatros, que eram centros de sociabilidade e de lazer, ou exemplares do morar das classes populares e uma grande parte da herança industrial. O boom, este sim imobiliário, nesta última década, passou o trator em bairros antigos de construções mais modestas, transformando-os em novas fronteiras econômicas e espaciais. Na mesa-redonda, também se lembrou da pressão dos projetos de renovação urbana, do discurso da obsolescência que decreta a morte de construções modernas, das obras de infraestrutura e serviços urbanos, fatores que compõe tensões sobre o patrimônio não reconhecido. Este quadro aponta para um trabalho ainda a ser feito, de reconhecimento e proteção, que vem se dando, pelo menos no caso do Brasil, sempre a reboque da dinâmica urbana. Enxergar, na realidade brasileira, uma obsessão preservacionista, à semelhança da discussão que fazem os europeus, justamente em um momento no qual as políticas de patrimônio, timidamente, se voltam para outras memórias, de outros sujeitos ausentes, nos parece uma visão elitista que tende a ocultar a natureza extremamente desigual do conjunto que se afirma ser memória coletiva.

A realidade coloca em xeque, assim, o discurso do esgotamento do processo de identificação e proteção. As ausências e exclusões nos colocam diante de outro problema que é o da desigualdade no reconhecimento e 
proteção. Valorizam-se determinados recortes, temas, memórias, enquanto se desprestigiam outros tantos. No caso brasileiro, Rubino (1996) foi quem primeiro mostrou a desigualdade do mapa do Brasil do passado, no qual se privilegiou determinados bens, fruto de determinados momentos históricos e determinadas estéticas, em detrimento da diversidade cultural que caracteriza o país, realidade que não mudou muito neste novo século. Sobre o nosso patrimônio nacional, a autora destaca que:

O conjunto eleito revê o desejo por um país passado, com quatro séculos de história, extremamente católico, guardado por canhões, patriarcal, latifundiário, ordenado por intendências e casas de câmara e cadeia, e habitado por personagens ilustres que caminham entre pontes e chafarizes. (op. cit, p. 98)

Igualmente, Canclini (1994) destaca o caráter desigual do patrimônio assinalando que, mesmo no México, onde os movimentos revolucionários conseguiram incluir bens, práticas e saberes dos indígenas e camponeses no rol de proteção legal, ainda há exclusões no que se refere aos setores populares urbano e operário. "O patrimônio serve, assim, como recurso para produzir diferenças entre os grupos sociais e a hegemonia dos que gozam de um acesso preferencial à produção e distribuição dos bens". (op.cit, p. 97)

No Brasil, a realidade mostra que, ao contrário de um excesso de patrimônio, estamos diante de um passivo patrimonial, pois ainda há muito a identificar e proteger, principalmente em relação aos grupos sociais não representados neste conjunto e ainda há que se resolver a carência de recursos para a conservação física e para a reinserção destes bens no tecido social.

Assim, é necessário relativizar uma leitura construída sobre as políticas de patrimônio como um universo totalizador, apontando para uma concepção dialética na qual se colocam em evidência as contradições e ambiguidades da realidade neste campo. Ao mesmo tempo em que se tem uma hipervalorização de determinados tipos de patrimônio e a sua reificação, este universo também contempla invisibilidades, ausências e exclusões, mostrando sua incompletude. 


\section{A PARTICIPAÇÃO SOCIAL NAS POLÍTICAS DE PATRIMÔNIO}

Ao tratar de um patrimônio urbano periférico intrinsecamente ligado ao cotidiano de seus moradores, ou seja, os antigos pueblos no Vale do México, Gabriela Lee colocou em evidência que os critérios de seleção ignoram como as pessoas percebem o patrimônio e o que estas populações consideram como de valor cultural.

Como toda política realizada de forma discricionária, a proteção do patrimônio se distancia cada vez mais dos sentidos e significados sociais atribuídos aos produtos da cultura, para impor um juízo de valor construído exclusivamente a partir de argumentos técnicos. Como é possível justificar valores culturais ou compreender o patrimônio como fato social, como nos diz Meneses (2012), unicamente pelo olhar técnico, tecnicista ou burocrático? Não se trata de opor um ao outro, como lembra o autor, nem de negar a importância do conhecimento teórico construído, mas de rever uma postura a respeito da avaliação e do reconhecimento do valor unicamente centrado nas lógicas profissionais corporativas.

Antes de se tornarem patrimônio oficial, os bens, objetos e práticas culturais fazem parte da vida cotidiana dos moradores dos lugares, estão incorporados ao imaginário, à identidade e à existência social. O patrimônio é, portanto, composto de histórias cotidianas que dão vida e garantem a presença nos lugares. A construção de relações respeitosas e sólidas com os lugares deveria ser o primeiro passo em direção às políticas de preservação mais democráticas. Aloísio Magalhães, então diretor do órgão público federal de proteção do patrimônio, o Instituto do Patrimônio Histórico e Artístico Nacional (Iphan) ${ }^{2}$, já apontava para esta preocupação, no começo da década de 1980.

O Iphan orientou-se pela ideia de cobrir todo o país, nem sempre ouvindo a comunidade sobre a preservação do patrimônio. Não sou a favor desta ideia. Esta postura elitista de tantos anos talvez seja consequência do próprio sistema político brasileiro, no seu sentido histórico e tradicional. A ação que vamos procurar empreender é tentar fazer com que a comunidade, nos seus afazeres e na sua vida, se conscientize de sua ambi-

\footnotetext{
2. O Instituto do Patrimônio Histórico e Artístico Nacional foi criado em 1936 como Serviço do Patrimônio Histórico e Artístico Nacional (Sphan).
} 
ência cultural. Isto é, temos que procurar dar à comunidade um status de vida que lhe permita entender por que determinado prédio está sendo preservado. Em outras palavras, a própria comunidade é a melhor guardiã de seu patrimônio. (MAGALHÃES, 1985, p. 184).

Para o então dirigente da instituição federal, a valorização do patrimônio depende do papel que este desempenha na vida cotidiana das cidades: se há uso comunitário ou presença na vivência coletiva, há alguma garantia de permanência de seu sentido social. Para Magalhães, isso é mais relevante do que direcionar os esforços da preservação no sentido da dinamização do turismo.

No caso dos monumentos em pedra e cal não faz sentido restaurá-los para que voltem depois a ser abandonados. É preciso reinserir esse bem na vida da comunidade. É necessário que ele volte a ser importante, volte a ser usado, diária, quotidiana e fortemente, pela comunidade. Primeiro porque é assim que ele vale e, segundo, porque é assim que ele se conserva. (MAGALHÃES, 1985, p. 185)

Por outro lado, não se trata de generalizar e pensar na participação social, hoje, como panaceia para solucionar todos os conflitos gerados pelo tombamento de bens; esta deve ser planejada e avaliada com critério, em cada contexto específico de atuação. Ela é de grande relevância em contextos de tombamentos de larga extensão, de conjuntos urbanos, sobretudo, quando estes envolvem setores populares, e, também, no caso de intervenções em patrimônio de forte apego e uso social, mas, sempre, quando se pretende que as políticas sejam realmente democráticas.

A participação social também não deve ser vista como sinônimo de realizar enquetes, pesquisas de opinião que resultem em dados quantitativos, gráficos ou em estatísticas, uma vez que o processo não trata de medir ou aferir valores atribuídos socialmente - a lógica é outra. Há experiências, instrumentos e estratégias próprias que permitem promover processos de envolvimento, diálogo e interlocução com os grupos sociais moradores do patrimônio. O trabalho apresentado por Gabriella Lee, que se valeu da realização de entrevistas a partir da construção de uma rede de relações locais e da elaboração de mapas mentais para com- 
preender identidades sociais e territoriais, indica uma metodologia de pesquisa sensível e possível de ser realizada em estudos de tombamento.

Para Meneses (2012, p.32), este é o "coração" da questão, uma vez que não se deve entender o universo do patrimônio simplesmente como um conjunto de coisas ou objetos que guardam valores em si mesmos, mas, antes de tudo, bens que são "mobilizados pelas sociedades, grupos sociais, comunidades, para socializar, operar e fazer agir suas ideias, crenças, afetos, seus significados, expectativas, juízos, critérios”. Assim sendo, apreender o significado deste patrimônio passa por processos que devem se dar em conjunto com os sujeitos, que são, também, seus intérpretes, e não a partir de visões absolutamente exteriores.

Isso implica que, na prática institucional, se desenvolvam outras formas de abordagem e de ação institucional, um novo fazer no que diz respeito aos estudos de tombamento. Trata-se do grande desafio atual das políticas de preservação do século XXI: superar a tradição e o conservadorismo discricionário. Trata-se, na verdade, de dar continuidade a um movimento de renovação conceitual que se deu a partir dos anos 1960, segundo Choay (2001), mas que no Brasil só se configurou nos anos 1980, com o processo de redemocratização e abertura política.

Esta renovação conceitual produziu uma mudança de olhar sobre o patrimônio nas instituições públicas, o que Marly Rodrigues chamou de "ampliação do universo cultural representado no patrimônio". No entanto, ela não repercutiu nos modo de fazer, nas práticas oficiais, que se mantiveram distante de um diálogo com os moradores dos lugares. Apesar de incorporarem novos objetos e de se construir uma argumentação teórica capaz de legitimá-los como parte da memória oficial, os procedimentos de tombamento não se transformaram muito em relação àquilo que vinha acontecendo, desde a década de 1930. Assim, as práticas do tombamento, ou seja, a maneira como se faz a preservação, ainda se encontra muito marcada por procedimentos burocráticos, verticais e sem diálogo com os grupos envolvidos.

É preciso renovar as práticas institucionais, no sentido de compreender os bens culturais a partir do olhar de seus interlocutores, dos grupos sociais que neles vivem. Se os objetos agora podem ser outros, é preciso, também, outras formas de atuação mais adequadas às especificidades de cada tipo de realidade. Segundo Nascimento e Scifoni (2015, p.132): 
Arriscando a incorrer em generalizações, observamos que a experiência no Brasil tem mostrado, de maneira geral, que as equipes técnicas que elaboram os estudos de tombamento ainda são muito refratárias à abertura de debate a respeito das decisões sobre a proteção. Contraditoriamente ao que diz a Constituição Federal em seu artigo 216, ou seja, de que a promoção e proteção do patrimônio cultural deve ser feita pelo poder público em colaboração com a comunidade, os discursos tem atribuído o papel de colaboração apenas no que diz respeito à responsabilidade por zelar pelos bens e muito pouco tem se atuado no sentido de processos de escolha e atribuição de valor de forma compartilhada. Assim sendo, a população tem o dever de zelar por ele, mas não tem tido o direito de se manifestar sobre aquilo que lhe impõe como herança coletiva.

Contudo, se participação social não é sinônimo de enquete, como já foi dito, também não deve ser confundida com a realização de audiências públicas ou de consulta pública via internet, pois estes mecanismos não garantem necessariamente um processo de interlocução. Não se trata de coletar a opinião e depois decidir às portas fechadas, em gabinete, mas de instaurar processos com decisões compartilhadas e negociadas, presencialmente, no coletivo.

No Brasil, a experiência de metodologias participativas em patrimônio cultural está prevista na legislação específica para o chamado patrimônio intangível, a qual considera os detentores destes bens como os intérpretes do seu patrimônio. Mas quando se trata do tombamento de bens materiais os procedimentos técnicos ainda se dão sem processos dialógicos, com raríssimas exceções ${ }^{3}$.

Como lembra Meneses (2012, p.38), "não basta um tratamento técnico-científico das questões: ele nunca dará conta de toda a problemática presente". A instauração de processos participativos nas localidades em estudo permite aos órgãos a criação de vínculos sólidos, necessários ao cotidiano da gestão do patrimônio e demonstra o respeito das instituições aos direitos de quem vive no lugar. $\mathrm{O}$ contrário, tombamentos sem

3. Exemplos de exceções foram os estudos de tombamento do Centro Histórico de Iguape e dos Bens Culturais da Imigração Japonesa em Registro, realizados no estado de São Paulo pelo Iphan. 
diálogo frequentemente geram indisposições, conflitos, tensões que podem inviabilizar as ações preservacionistas.

\section{A URGÊNCIA DE UM OLHAR INTEGRAL SOBRE O PATRIMÔNIO}

Marly Rodrigues destacou, em sua apresentação das experiências brasileiras de preservação, o problema da distância entre os atuais procedimentos técnicos de identificação e seleção frente aos novos conceitos consolidados a partir, principalmente, da Constituição Federal de 1988. Lembrou a importância da realização de inventários como orientadores de uma política de salvaguarda, mas, ao mesmo tempo, de sua contínua ausência nas práticas de preservação.

Em que pese às possibilidades criadas pelos dispositivos constitucionais e às novas categorias de patrimônio e seus instrumentos específicos, particularmente no que diz respeito ao patrimônio intangível e à paisagem cultural, as práticas ainda estão profundamente arraigadas em uma visão tradicionalista, a qual Marly Rodrigues tem chamado de "ortodoxia do patrimônio".

Exemplos disso estão no cotidiano e no "chão de fábrica" da preservação. Em 2009, o órgão federal de patrimônio instituiu uma normativa para regulamentar a proteção às paisagens culturais, por meio do instrumento chancela da paisagem cultural. Instrumento inovador que permite olhar para o território reconhecendo dinâmicas culturais relacionadas aos grupos sociais, manifestações imateriais articuladas à base espacial, materialidades construídas e pedaços de natureza em comunhão com a vida humana.Além de inovador, do ponto de vista de construção do objeto de preservação, a metodologia de estudo da chancela da paisagem cultural implica na criação de uma rede de proteção, articulando os grupos sociais locais em ações participativas e compromissos compartilhados na preservação do patrimônio.

Pergunta-se, de 2009 a 2016, quantas paisagens culturais foram objeto de reconhecimento pelo Iphan? Uma única experiência, a realizada em Santa Catarina e denominada Roteiros Nacionais da Imigração. 
Outros estudos foram realizados pelo órgão ${ }^{4}$, contudo encontram-se totalmente paralisados, sem encaminhamento.

O prejuízo com a paralisação é imenso, já que esta pode ser considerada a experiência de patrimônio com maior compromisso social, uma vez que voltada à melhoria das condições de vida e de valorização de contextos locais. Segundo define a Carta da Bodoquena (IPHAN, 2007): a paisagem cultural, em última instância, diz respeito mais às pessoas que às coisas, pois as premissas da conservação e preservação devem atender às necessidades humanas, quer de conhecimento ou de pertencimento a uma cultura e um lugar.

Neste sentido, o projeto Barcos do Brasil, por exemplo, buscou identificar lugares pouco conhecidos do litoral brasileiro nos quais ainda permaneciam encravadas, no cotidiano de vida dos grupos sociais, técnicas de carpintaria naval, em situação de grande pressão de desaparecimento em função da modernização que tem substituído os barcos de madeira por outros materiais industriais, tais como fibra de vidro ou alumínio. Além do saber-fazer tradicional da carpintaria naval, esses contextos litorâneos combinavam pesca artesanal e manifestações imateriais vivas no tecido social. Buscava-se, assim, com a chancela, não somente um inventário de lugares e usos, mas realizar um diagnóstico de situação de sobrevivência, base para a implementação de ações de salvaguarda que resultassem no fortalecimento desse uso tradicional, combinado com ações públicas de melhoria de condições de vida e trabalho. (IPHAN/DEPAM/COORDENAÇÃO DA PAISAGEM CULTURAL, 2011).

Nesta mesma perspectiva social, destaca-se o estudo da Paisagem Cultural do Vale do Ribeira, realizado a partir de 2007. A região, com seu rico potencial patrimonial, ficou durante o século XX à margem dos processos de valorização econômica conduzidos pela modernização das ferrovias e industrialização ocorridas em São Paulo. Conhecida pelos seus índices de pobreza e pela ausência de políticas públicas, o Vale do Ribeira,

4. Alguns exemplos de estudos realizados pelo Iphan são: o projeto Barcos do Brasil, que trabalhou em contextos litorâneos singulares do patrimônio naval brasileiro, como a Vila de Elesbão (Amapá), Pitimbu (Paraíba), Valença (Bahia) e Camocim (Ceará); e os projetos envolvendo comunidades ribeirinhas e pesqueiras como o Vale do Ribeira, em São Paulo, e a Foz do Rio São Francisco, em Sergipe e Alagoas. 
até 2007, quando se iniciou o estudo, estava fora do mapa do patrimônio federal, o que reforça o significado social do trabalho. A proposta de paisagem buscou criar um instrumento de proteção que pudesse ser um aliado das populações tradicionais, como caiçaras, quilombolas e ribeirinhos, na permanência na terra e na manutenção e continuidade de seu modo de vida. Política cultural articulada às necessidades sociais de uma região de alta vulnerabilidade.

Neste contexto, a paralisação dos estudos traz um duplo prejuízo: de um lado reafirma a ausência de instrumentos legais que poderiam garantir a continuidade e proteção deste rico patrimônio; de outro lado, cria um sentimento de frustração nos grupos sociais que foram envolvidos nestes estudos.

O trabalho com a categoria de paisagem cultural apresentava-se como possibilidade de incorporar metodologias novas e um olhar mais integrado ao patrimônio, sem necessariamente distinguir entre as categorias material, imaterial, natural, arqueológica. $\mathrm{O}$ recorte territorial que o instrumento da chancela da paisagem cultural cria possibilita compreender o patrimônio como ele é, na realidade, ou seja, integrado, vivo e completo, enquanto os outros instrumentos o transformam em fragmentado, pontual, parcial.

Os estudos de chancela da paisagem cultural se aproximam muito do trabalho apresentado por Gabriela Lee, sobre os pueblos do Vale do México. Em comum, temos: critérios de valoração que levam em conta como os moradores percebem o patrimônio; uma visão integral da realidade que contempla para além das edificações e arquiteturas, os espaços públicos, as referências espaciais, os caminhos, os usos e apropriações sociais; a compreensão da construção da identidade ao mesmo tempo, social e espacial-territorial.

Por fim, é importante destacar que, dentre as novas metodologias capazes de produzir um olhar mais integrado sobre o patrimônio, encontram-se as experiências dos chamados Inventários Participativos (VARINE, 2013; SÁ et al, 2016; VIEIRA NETO, 2016). Utilizados quer na Museologia Social ou na Educação Patrimonial, estes inventários se constituem em instrumento de conhecimento construído de forma coletiva e dialogada, na qual as comunidades locais se tornam sujeitos da seleção e 
da atribuição de valor, mas, sobretudo, protagonistas da produção de um saber sobre os bens.

Os inventários participativos se tornam uma opção metodológica nos esforços de aproximação das instituições de patrimônio nas localidades, quer sejam lugares ainda em estudo para tombamento ou já tombados. Segundo um dos protagonistas de uma experiência pioneira realizada em 1998, na cidade de Viamão, Rio Grande do Sul, os inventários participativos são, antes de tudo, um direito das populações de participar da construção de uma memória oficial, do que deve ser lembrado a partir da preservação de seus suportes materiais.

A ideia desta forma de inventariar, buscando a participação direta do cidadão, e não apenas a opinião técnica, não está simplesmente na concepção óbvia de que as ações públicas devem ser participativas para alcançarem ampla representatividade social. Nem tão pouco na ideia a seguir decorrente, de que envolver a comunidade é uma forma de "educação patrimonial" e de conscientização social. Um pouco mais que isto, a concepção de Inventário Participativo tem por trás de si o debate sobre o "direito de decidir o que é e o que não é possível de preservação e, portanto, merece todos os esforços do poder público para a sua valorização, difusão e preservação", o que evidentemente deve ser de todos, questão esta colocada primeiramente pela Constituição Cidadã de 1988. E ainda uma outra, consequência natural desta participação ampla, desta abertura no direito de valorar os bens patrimoniais que é o evocamento de bens de natureza diversas, tangíveis e intangíveis, móveis e imóveis, documentais, memória de vidas, sítios arqueológicos, ecológicos e paisagísticos, de acordo com a reabrangência do conceito de Patrimônio Cultural estabelecida pelo artigo 216 da CF, numa prova definitiva da superação do critério da monumentalidade e da influente tradição arquitetônica. (ORTIZ, 2001, grifo nosso)

\section{CONSIDERAÇÕES FINAIS: O PATRIMÔNIO NA TOTALIDADE URBANA}

As questões problematizadas neste artigo tiveram como ponto de partida as discussões da apresentação de três experiências de práticas de patrimônio: 
França, México e Brasil. Buscou-se desdobrá-las em novos caminhos de argumentação em um diálogo com outros autores.

O quadro comparativo dessas experiências sinaliza para uma conjuntura patrimonial marcada por ausências, exclusões e incompletude, que reforçam a constatação sobre a natureza desigual do patrimônio. A contradição está no coração das políticas de patrimônio, já que se afirma ser universal, coletivo, de todos, mas é, na prática, marcadamente desigual, hierarquizado socialmente, privilégio de poucos e excludente.

Já virou clichê afirmar que nunca se falou tanto em patrimônio como nos tempos atuais, mas não estaríamos lendo os sinais de forma invertida? Afirmar que se ampliou o debate público, que ocorrem mais eventos científicos ou que o tema está mais presente nos meios de comunicação ou nas escolas, que há maior produção acadêmica, que se presencia mais mobilização e demanda social, tudo isso, realmente, afirma a emergência de uma questão patrimonial? Podemos concluir que há maior relevância do patrimônio nas políticas públicas ou que estamos obcecados pela preservação? Até que ponto o olhar não tem sido otimista demais, pelo menos em relação à realidade brasileira?

Instituições públicas a quem cabe a tutela do patrimônio estão, cada vez mais, sucateadas; os orçamentos não cabem nas necessidades reais da preservação; os técnicos, muito bem qualificados em seu dever, são cada vez mais desvalorizados do ponto de vista salarial, fato que produz esvaziamento dos quadros profissionais; e os interesses econômicos e políticos se sobrepõem constantemente, não só a preservação do patrimônio, mas até mesmo ela, passam por cima da legislação protetora! Esta é a realidade do patrimônio no Brasil, que coloca em xeque a visão otimista de que há uma inflação patrimonial.

Sobre a presença do patrimônio na ordem do dia, Fernando Carrion Mena (2014, p.81), avalia que:

Me da la impresión de que esto no es casual, yo creo que está tan presente el tema del patrimonio porque nunca se lo había destruido tanto. En otras palabras, estamos en un momento de crisis, en una coyuntura patrimonial, porque estamos viviendo un proceso muy fuerte de destrucción del patrimonio. 
Para este autor, o fato de se falar tanto em patrimônio na atualidade não significa necessariamente que estamos preservando mais, ou estamos em uma situação confortável. Ao contrário, o poder de destruição e desaparecimento dos suportes materiais de memórias tem sido avassalador e abarca uma variedade de situações que vai daqueles bens não legalmente protegidos, até àqueles que já dispõem de amparo legal. O autor lembra, também que, o patrimônio protegido tem se tornado privilégio de alguns, instrumento de exclusão social pela gentrificação, fonte de perpetuação de uma história oficial naturalizada, sem lutas e conflitos.

A leitura da conjuntura patrimonial indicando a crise, como faz Mena (2014) parece estar mais próxima da realidade do que o debate tem apontado.

\section{REFERÊNCIAS}

CANCLINI, Néstor G. O Patrimônio cultural e a construção imaginária do nacional. Revista do Patrimônio Histórico e Artístico Nacional, Brasília, n. 23, p.95-115, 1994.

CHOAY, Françoise. A alegoria do patrimônio. Tradução: Luciano V. Machado. São Paulo: Estação Liberdade/Ed.Unesp, 2001.

INSTITUTO DO PATRIMÔNIO HISTÓRICO E ARTÍSTICO NACIONAL (IPHAN). Carta da Bodoquena ou Carta das Paisagens Culturais e Geoparques. Mato Grosso do Sul: Iphan, 2007.

INSTITUTO DO PATRIMÔNIO HISTÓRICO E ARTÍSTICO NACIONAL (IPHAN)/ DEPARTAMENTO DE PATRIMÔNIO MATERIAL (DEPAM)/ COORDENAÇÃO DA PAISAGEM CULTURAL. Reflexões sobre a chancela da Paisagem Cultural Brasileira. Brasília: Iphan, 2011.

JEUDY, Henri-Pierre. Espelho das cidades. Tradução: Rejane Janowitzer. Rio de Janeiro: Casa da Palavra, 2005.

MAGALHÃES, Aloísio. E Triunfo? A questão dos bens culturais no Brasil. Rio de Janeiro: Nova Fronteira, 1985.

MENA, Fernando Carrion. Urbicidio o la noción del olvido. In: XV Seminario sobre Patrimonio Cultural, 2014, Chile.

MENESES, Ulpiano T.B. O campo do patrimônio cultural: uma revisão de premissas. In: I Fórum Nacional de Patrimônio Cultural. Brasília: Iphan, 2012. v.1.

NASCIMENTO, Flávia B.; SCIFONI, Simone. Preservación del patrimônio cultural y participación social: las experiências em Iguape y Registro (San Pablo, Brasil). Revista América Patrimonio, Chile, n. 7, p.128-136, 2015. Disponível em: <http://www.revistaamericapatrimonio.org $>$ Acesso em: 2 mar. 2016.

ORTIZ, Vitor. Inventário participativo de Viamão. Jornal Quarteirão, n. 45, nov/dez, 2001, Rio de Janeiro.

RUBINO, Silvana. O mapa do Brasil passado. Revista do Patrimônio Histórico e Artístico Nacional, Brasília, n. 24, p.97-105, 1994. 
SÁ, Aleckssandra A.S.; SERRADELA, Larissa I.; LÉO NETO, NIVALDO A. Tiririca dos Crioulos: um quilombo indígena. Carnaubeira da Penha-PE: Associação dos Remanescentes do Quilombo Tiririca, 2016. Disponível em: <http://www.culturadigital.br/titiricadoscrioulos >

SANTOS, Cecília R. dos; MARQUES, Sonia. Maldita memória. Sobre a tirania da memorização e os anacronismos de um patrimônio refém. Arquitextos, São Paulo, ano 15, n. 175.00, Vitruvius, dez. 2014. Disponível em: <http://www.vitruvius.com.br/revistas/read/arquitextos/15.175/5373>. Acessado em: 2 mar. 2016.

VARINE, Hugues de. As raízes do futuro. Tradução: maria de Lourdes P. Horta. Patrimônio a serviço do desenvolvimento social. Porto Alegre: Medianiz, 2013.

VIEIRA NETO, João Paulo. Inventários participativos do patrimônio cultural: participação social e produção colaborativa de conhecimento nos processos de patrimonialização. In: INSTITUTO DO PATRIMÔNIO HISTÓRICO E ARTÍSTICO NACIONAL (IPHAN)/COORDENAÇÃO DE EDUCAÇÃO PATRIMONIAL (CEDUC). Inventário participativo do patrimônio cultural. Manual de Aplicação. Brasília: Iphan, 2016 (no prelo).

\section{Recebido}

07/03/2016

Aprovado

16/06/2016 